\title{
Knowledge And Perception of Women Regarding Bilateral Tubal Ligation In Southwest Nigeria
}

\author{
Akpor $\mathrm{OA}^{1} *$, Fadare $\mathrm{RI}^{1}$ and Ekanem $\mathrm{EI}^{1}$ \\ ${ }^{I}$ (Department of Nursing, College of Health Sciences, Afe Babalola University, Ado Ekiti, Nigeria)
}

\begin{abstract}
Bilateral tubal ligation (BTL) is a procedure considered as permanent, although sometimes reversible, it is seen as a highly effective method of contraception. In Nigeria only $0.1 \%$ of women aged 14 - 44 years use female sterilization as a contraceptive method, the acceptance rate is low. The purpose of the study was to investigate the knowledge and perception of women regarding bilateral tubal ligation (BTL) based on Kolcaba's Theory of Comfort. A qualitative contextual exploratory approach was used. Data collection was by means of audio-taped semi-structured interview and Tesch's content analysis style was utilised. The sample size for the study was determined by saturation of data and consisted of 18 women admitted in the maternity section of the hospital. The findings showed that all participants in the study were aware of family planning; only one participant used BTL as a method of choice. Awareness of BTL among participants showed that two third were aware of BTL as a method of family planning, one third of the participants stated that BTL is a risky method of family planning, likewise the majority believed it is bad and should not be practiced and almost two thirds of the participants indicated that they will not recommend BTL for women. Family planning is a vital aspect of safe motherhood for women, so nurses in every facet of the health care system should step up to the responsibility of being a health educator and educate women on the benefits of BTL as well as advocate for its availability at a reasonable cost. Family planning is a major issue that must be discussed with women once they are found to be pregnant.
\end{abstract}

Keywords: Bilateral tubal ligation, knowledge, perception, women

\section{Introduction}

Family planning is a word that has been heard frequently in the medical profession. It can be said to be as old as man himself and to this effect, there are more than 500 definitions of family planning. World Health Organization [1] defined family planning "as something that allows individuals and couples to foresee and achieve their desired number of children as well as the spacing and timing of their births. It is accomplished through use of different contraceptive methods and the treatment of involuntary infertility. The ability of a woman to space and limit her pregnancies has a direct effect on her health and well-being as well as on the outcome of each pregnancy [1].

Namboze also [2] described family planning as activities by individuals and couples to plan the timing, number and spacing of the children that they desire in order to promote the health and wellbeing of the family group. Nevertheless the most significant definition of family planning was according to WHO [1) because it buttresses the importance of family planning on the woman's health and outcome of her pregnancy. In Nigeria, family planning has remained a delicate issue that is still reluctantly being accepted based on religious belief and the perception that it is synonymous with population control [3]. Consequently, this makes it difficult for women to come out openly or voluntarily to seek for ways to improve their reproductive health. Various factors have been identified as the reasons for the low contraceptive prevalence; they include poverty, ignorance, low educational level, desire for large family size, poor access to contraceptive services, community pressure, male or husband dominance, and religious beliefs $[4,5]$.

Kabir et al. [5] stated that permanent methods of contraceptive like bilateral tubal ligation (BTL) are more acceptable in the western world, while intrauterine contraceptive devices (IUD) are more commonly used in the western part of Nigeria. These differences are probably due to social, economic, educational, and religious factors [6]. Previous studies by Ekewmpu [7] and Haggi [8], both from Zaria Northern Nigeria, showed an increase in the number of clients swapping from one method of contraceptive to another with a trend towards Norplant and injectable over the last 20 years. As Nigeria strives to achieve the goals of the millennium declaration particularly the reduction of maternal mortality, one of the key interventions is the promotion and usage of effective family planning services [9]. Nearly a decade into the millennium, contraceptive prevalence rates in some parts of Nigeria are still reportedly low [10].

Bilateral tubal ligation (BTL), also referred to as female sterilization is a procedure considered as permanent, although sometimes reversible, it is seen as a highly effective method of contraception. It may be performed after a C-section while the patient is still anesthetized. It can be puerperal in which case the surgery is performed 24 to 48 hours following delivery or interval that is, the operation is done beyond three (3) months 
following delivery or abortion. It can also be concurrent with termination of pregnancy (MTP) especially in the urban centres. Tubectomy is the widely accepted procedure with either abdominal or vaginal approach [11]. The surgery involves blocking or cutting the fallopian tubes and may require a general, spinal or epidural anesthetic. BTL is the most popular method of terminal contraception all over the world $[11,12]$.

In Africa, the acceptance rate of BTL is low because of deep rooted socio-cultural and religious barriers, poverty, inadequate counseling, limited facilities and trained personnel [12, 13, 14]. A study in the Southern Nigeria showed that only $0.7 \%$ of clients had BTL [10]. Common indications for BTL are grand multiparity, two or more previous Caesarean sections, ruptured uterus and medical disorders of pregnancy. While in United States of American (USA) up to 11 million women aged 15 - 44 years rely on BTL for contraception [15]. The ability of women to start a successful, uninterrupted and suitable contraceptive method is influenced by different factors; such as poor access to the health center, community and cultural attitudes as well as individual attitude can all be considered as obstacles to the use of appropriate and effective method of family planning for women. Due to the increasing number of therapeutic abortion, lack of awareness of the Nigerian woman of her right to a have a healthy reproductive life, the stress of family and societal demands on women as well as their ability to be able to cope with motherhood and her role in society, hence, this study explored the knowledge and perception of women regarding bilateral tubal ligation among women of child bearing age in Western Nigeria.

\section{Theoretical framework}

The theoretical framework for the study is Kolcaba's Theory of Comfort [16]. Kolcaba's Theory of Comfort is a family theory that was first developed in the 1990s by Katharine Kolcaba. It is a middle-range theory for health practice, education, and research. It has the potential to place comfort in the forefront of healthcare. According to the model, comfort is an instant necessary outcome of nursing care, according to Kolcaba, comfort is the product of holistic nursing art. Kolcaba described comfort existing in three forms: relief, ease, and transcendence.

If the specific comfort needs of a patient are actualized, the patient experiences comfort in the sense of relief. For example, a patient who receives pain medication in post-operative care is receiving relief comfort. Also, ease addresses comfort in a state of contentment; For example, the patient's anxieties are calmed. Finally transcendence is described as a state of comfort in which patients are able to rise above their challenges. Also according to the Kolcaba's Theory of Comfort [16], the four contexts in which patient comfort can occur are: physical, psycho spiritual, environmental and sociocultural. The Theory of Comfort considers patients to be individuals, families, institutions, or communities in need of health care. The environment is any aspect of the patient, family, or institutional surroundings that can be manipulated by a nurse or loved one in order to enhance comfort. In the model, nursing is described as the process of assessing the comfort needs of a patient, developing and applying appropriate nursing care plans as well as assessing the patient's comfort after the implementation of the care plans. Nursing care includes the intentional assessment of comfort needs, the design of comfort measures to address those needs, and the reassessment of comfort levels after implementation.

The theory is applicable to the study because it will help to explain how women of child bearing age can achieve comfort, through relief and ease regarding their reproductive lives. Thus, they will be able to make an informed contraceptive choice that will transcend to a happy family life. As stated above, Kolcaba's Theory of Comfort [16] describes comfort as existing in three forms; relief, ease and transcendence as well as the four contexts in which patient comfort can occur; physical, psycho spiritual, environmental and sociocultural.

Relief comfort: Bilateral tubal ligation (BTL) will be a relief comfort for women who have high parity status, recurrent ectopic pregnancy, recurrent therapeutic abortions and women who need a permanent method of contraceptive, since this method of family planning is a onetime procedure and does not demand recurrent visit to the hospital or change. This way, women have no fear of unintended pregnancy and are free from sudden gynecological emergencies.

Ease comfort: As stated earlier, BTL is a onetime procedure that is a very easy and safe method of family planning. With the procedure done, the woman is poised to have a very healthy and active reproductive life without the fear of pregnancy or possible side effects of other contraceptives.

Transcendence: With the choice of using BTL as a method of family planning, women are able to go about their lives, achieve their dreams and live a happy life. With the choice of BTL as a family planning method, women with known gynecological problems are able to rise above their problems because of the benefits it proffers.

Physical: For reproduction to be achieved, the body needs to be healthy and anatomically sound. For women to achieve comfort in their reproductive life, their bodies need to be healthy and free from any form of stress. The body after child birth needs to heal and go back to its pre gravid state and for this to occur a good choice of family planning method such as BTL needs to be adopted. 
Psycho spiritual: The choice of a family planning method is usually made by the couples. This is so, because the couples enjoy the choice they have made and are not left out in the decision making process. In a country like Nigeria where it is still believed that a woman should be the one responsible alone for family planning activities, the women will need to be guided through making the right choice. In the case of BTL, women should be given thorough counseling and psychological support as this will strengthen them through the process and spouses should be involved in the process as this will strengthen the wife to go through the process. Religious beliefs of women should not be ignored as this also plays a great role in a woman's decision to have BTL or not.

Environmental: An individual is a reflection of his environment, thus, a woman is more likely to adopt BTL as a method of family planning if there are women in her environment who have undergone the procedure and are happy using it. Also, she will adopt the method if her spouse and other family members gives necessary support.

Sociocultural: Society has always played a great role in individual decision making most times, it is a very strong determinant in decision making. Women considering BTL may experience pressure from the society and culture may also influence her decisions. Most cultures in Nigeria believe a woman should not manipulate her body to prevent pregnancy, as it is believed such will affect her sexuality on reincarnation so this will also affect the possibility of women adopting BTL as choice of family planning method.

\section{Methodology}

The study was conducted at the Federal Teaching Hospital Ido- Ekiti, Ekiti State,in Western Nigeria. The strategy for the study was exploratory while the research design was qualitative. The target population was women in the maternity section of the hospital. The sampling method was purposive. Inclusion criteria for the study were women between the ages of 18- 45 years, married, living with their husbands and have parity status not less than one, who reside in the study area and willingness to participate. The sample size was determined by saturation of data, which was achieved when 15 participants had been interviewed. A total of 15 interviews were analyzed with new categories and 3 interviews analyzed without new categories evolving.

Data gathering was through audio-taped semi-structured interviews. To guide the interviewer, an interview schedule was developed, also two pre-test interviews was conducted. Before the commencement of the study, approvals were obtained from the Research Ethic Committee of Afe Babalola University and from the Research Ethic Committee of the Federal Teaching Hospital Ido- Ekiti, both in Ekiti State. Prior to any interview, each participant's right was explained and informed consent was obtained, as well as the permission to use an audio recorder. To ensure privacy, the interview was done in a private room with only the participant and the researcher present. All participants were interviewed within a period of five weeks (February to April, 2016). For data analysis, content analysis using open coding according to Tesch's approach was used. To ensure trustworthiness, strategies such as interpersonal relationship and trust building, triangulation of data gathering methods, peer examination, member checking, and authority of the researcher, dense description structural coherence and dependability audit were employed.

\section{Interpretation of findings}

The findings of the study are presented according to the themes and sub-categories generated from the data (TABLE 1). Each of the themes is described with a summary of the categories. In this study, a total number of eighteen participants were interviewed $(n=18)$. As shown in TABLE 2, the majority $(55.5 \%)$ of the participants was within the age group of $30-39$ years of age and had tertiary education. Two-third (66.7\%) of the participants was Yoruba and had between 1 to 3 children.

\section{Theme 1: Awareness of family planning}

With regards to participants meaning of family planning, two third (12 of 18) of the participants said it is a method of preventing unwanted pregnancy and sexual transmitted diseases (STD), while the remaining (6 of 18) described it as a method of child spacing and a way to protect one's home and self. Two of their responses were:

"It is used to prevent the issue of unwanted pregnancy and sexually transmitted diseases"

"I was taught at the antenatal clinic that it is used for child spacing and protect one's home and self",

\section{Source of information:}

Participants were asked about their source of information, more than two third (13 of 18) mentioned that got their information about family planning from the antenatal clinic, relatives and television. The remaining ( 5 of 18) stated that they received information from the school, church and friends. Below are some of their comments:

"It was during the antenatal section the nurse educated us on family planning". 
"My sister in-law was the one that told me about it and I also got some information from the television".

"I first got the information in my secondary school days and during a marriage seminar in church".

On participant choice of family planning method, only 2 of 18 of the participants said they are not using any family planning method, one participant each are using BTL and oral contraceptive respectively, almost one third (5 of 18) are using condom and withdrawal method while half (9 of 18) of the participants are using inter uterine contraceptive device (IUCD). In terms of health education on family planning, more than two third (13 of 18) indicated family planning is for couples and it is best gotten from the hospital, less than one third ( 3 of 18) believed that it has side effects and it is not $100 \%$ effective against pregnancy while only two participants mentioned that contraceptives must fit your body type and your husband must be involved. Some of the comments are:

"It is for couple and they must go to the hospital to get the one that suits them".

"Family planning is good but they all have side effects and they cannot be 100\% effective against pregnancy".

\section{Theme 2: Participants knowledge of BTL}

Awareness of BTL among participants showed that two third (12 of 18) were aware of BTL and the remaining one third ( 6 of 18 ) were not aware of BTL. One response was:

"Yes I know about it. It was called womb tie in my own antenatal clinic".

With regards to source of information on BTL, only one participant got her information from family planning training, three participants got their information from school, one third (6 of 18) obtained their information from the antenatal clinic and the remaining two participants obtained their information from books and church seminars. Some comments made are as follows:

"I am a family planning provider and I was educated on BTL that is how I got to know about it".

"I got to know about BTL when I went for my antenatal appointments".

In terms of meaning of BTL, almost two third (11 of 18) of the participants said it is an operation performed by the doctor to stop pregnancy, one third (6 of 18) of the participants stated that it is a risky method of family planning to practice while the remaining one participant believed it is economical, gives freedom and peace of mind to the woman. Below are some of the participants' comments:

"It is a very nice method of family because it is economical and you don't have to worry about you contraceptive finishing or getting a new one"

"It is a very risky thing to do as a woman. What if something goes wrong?"

\section{Theme 3: Participants perception of BTL}

With regards to participants belief regarding BTL more than one third (7 of 18) believe it is good and can be used if desired by a woman but the remaining (11 of 18) believe it is bad and should not be practiced. The followings are some of their comments:

"BTL is good and if a woman thinks she is ok with the number of children she has she can opt for it".

"It is not safe, what if the woman dies in the process of operation, no it is too bad, and it must not be practiced".

Participants were asked about their religious stand on BTL, one third (6 of 18) of the participants had no religious stand on BTL, also one third each stated that it was against their Christian and Muslim faith respectively. Some of their interesting comments are:

"I do not see any problem with BTL, if a woman wants it she can go for it. I can't remember any part of my religion that forbids it."

"God said we are wonderful and fairly made, so why should one seek to destroy what God has done. According to my bible God said we should be fruitful and multiply."

"I don't think is right, there is nowhere in my Quran that says a woman should cut any part of her body."

Participants were asked if they can recommend BTL for others, more than one third (7 of 18) said they would recommend BTL for women who had the following criteria; who were above 45 years of age, have five children and above and done with child birth. The remaining 11 of 18 stated that they will not recommend BTL for women because of the following reasons, it is bad, the woman may later desire to have children and it will give room for the husband to misbehave. Some of the comments are:

"Yes I will recommend BTL for women, but she must be sure it is what she wants and must not be less than 45years of age, she must have at least five children"

"No I will not recommend BTL for another woman because she may later desire more children"

"I will not recommend BTL for any woman because it is a very risky thing to do and will make her husband take advantage of it to mess around with other women"

\section{Discussion}

The provision and expansion of family-planning services are a public-health need and a national development priority for many countries across Sub-Saharan Africa [17]. The Federal Government of Nigeria established a family planning policy within the primary health care framework in 1989 and since over a decade 
ago, Otolorin et al [12] stated that family planning in Nigeria remains at infancy, with a low contraceptive prevalence rate of $11 \%$. Even with renewed efforts at the turn of the century in achieving the goals of the millennium declarations, the target of this policy is yet to be met. Although all participants in the study were aware of family planning services but many Sub-Saharan African countries have persistently high rates of unmet need for family planning and low rates of contraceptive use [12. 14]. The low levels of utilization are typically a function of both the limited capacity of the health system and the framework within which family planning services are delivered. According to Igberase and Ebeigbe, [18], the maternal mortality figure in Nigeria is very high and there is therefore a need for a reliable contraception such as bilateral tubal ligation. The acceptance rate of BTL in Africa is low because of deep rooted socio-cultural and religious barriers, poverty, inadequate counseling, limited facilities as well as lack of trained personnel [12, 13, 14]. Few reports have been documented on BTL in Nigeria; it was revealed that only $0.1 \%$ of women aged 14 - 44 years use female sterilization as a contraceptive method in the late 1980s [12]. In a study conducted in the Northern Nigeria, it was shown that the acceptance rate of BTL by the clients was $21.7 \%$ amongst other contraceptive methods [19]. Likewise, a study in the Southern Nigeria showed that only $0.7 \%$ of clients had bilateral tubal ligation [10]. In consistent with this study, only ( 1 of 18) of the participant used BTL as a method of family planning.

Also, in this study, although two third (12 of 18) of the participants were aware of BTL, one third (6 of 18) of the participants stated that BTL is a risky method of family planning, likewise the majority (11 of 18) believe it is bad and should not be practiced and almost two third (11 of 18) of the participants indicated that they will not recommend BTL for women. Since tubal sterilization procedures are designed to be permanent, proper patient counseling and informed consent is of paramount importance preoperatively in preparing the patient for a sterilization procedure [19]. The decision for sterilization should be made on an entirely voluntary basis following appropriate discussion regarding risks, benefits, and alternatives. Patients should understand that tubal sterilization is intended to be permanent and if they are not sure of their decision, there are effective longacting reversible contraceptive methods (such as implants and intrauterine contraceptives) that have failure rates as good as or better than permanent surgical sterilization [20]. Various materials are available to assist the physician in patient counseling and in obtaining informed consent. The failure rate of a properly performed sterilization operation is less than $1 \%$ and there are no consistent differences in efficacy documented among the standard techniques used today [20]. According to a study conducted by Waheeb et al [21] in Egypt, the majority of the participants in a focused group discussion classified BTL as not permissible religiously, some believe that tubal ligation damages the perfect God-created structure of the human body will lead to divine punishment, this is in accordance with the study findings as two third (12 of 18) stated that BTL was against their religious beliefs.

\section{Conclusion and Recommendation}

The study was carried out to ascertain the knowledge and perception of women on bilateral tubal ligation as a choice of family planning. The results gathered showed that all the participants are aware of family planning services but only one participant used BTL as a method of choice. Also, the majority believes BTL is bad and should not be practiced. Family planning is a vital aspect of safe motherhood for women, so nurses in every facet of the health care system should step up to the responsibility of being a health educator and educate women on the benefits of BTL as well as advocate for its availability at a reasonable cost. Family planning is a major issue that must be discussed with women once they are found to be pregnant. It is the sole responsibility of the nurse to educate women about different family planning methods. Moreover, selected centers should be chosen and upgraded (through training, providing of necessary equipment etc.) to become centers of excellence for providing tubal ligation service so as to boost its acceptance.The limitations of this research were the limited time frame for the study and the purposive sampling of the participants reduces the generalizability of the findings.

\section{Acknowledgements}

The authors are grateful to the Management and Ethics Committee of Afe Babalola University and Federal Teaching Hospital Ido-Ekiti Ekiti State for granting the permission to conduct the study and every woman who participated in the study.

\section{References}

[1] World Health Organization, WHO Family planning, 2016 [Online]. Available from: http://www.who.int/topics/family_planning [Accessed: 1/4/2016].

[2] J. M. Namboze, Maternal health services: in Principles and practice of community health in Africa ( University Press: Ibadan, 1985).

[3] A.Y. Isah and E.I. Nwobodo, Family planning practice in a tertiary health institution in north-western Nigeria, Nigerian Journal of Clinical Practice, 12, 2009, 281-3.

[4] E.E. Emuveyan, and R.A. Dixon, Family planning clinics in Lagos; Nigeria Clients, methods accepted and continuation rates, Nigerian medical journal, 28, 1995, 19-23. 
[5] M. Kabir, Z. Iliyasu, I.S. Abubakar, and B.S. Mage, The role of men in contraceptive decision making in Fashekara village, Northern Nigeria, Tropical Journal of Obstetrics and Gynecology, 1990, 18-21.

[6] M.T. Ibrahim, and A.U. Sadiq, (1999). Knowledge, attitude, practices and beliefs about family planning among women attending primary health care clinics in Sokoto, Nigeria, Nigerian Journal of Medicine 8, 1999, 154-8.

[7] C.C. Ekewmpu, (1990). The realities of VSC service at Zaria management, socio-cultural and medical issues. Tropical Journal of Obstetrics and Gynecology, 1990, 35-6.

[8] D.N. Haggai, The Norplant experience in Zaria: A ten year review, African Journal of Reproductive Health, 7, $2003,20-4$.

[9] United Nations: Millennium Declaration, 2000 [Online]. Available from: http://www.un.org $>$ devagenda $>$ millenium [Accessed 4/4/16].

[10] J.D. Ojule, and D.A. Macpepple, Family planning practice in a Tertiary Health Institution in Southern Nigeria, West African Journal of Medicine 30 ( 3 ), 2011, 178.

[11] D.C. Dutta, Textbook of Obstetrics (London: New Central Book Agency, 2011).

[12] E. O. Otolorin, E.A. Falase, I.A. Olayinka, and O.A. Ladipo, Attitudes of Nigerians to voluntary sterilization: A Survey of an Urban Population, Tropical Journal of Obstetrics and Gynecology, 2, 1990, 18-21.

[13] A. Omole-Ohonsi, A. Ashimi, and R.A. Attah, (2010). A Review of family planning methods used in Kano, Nigeria. Nigerian Journal of Clinical Medicine, 2, 2010, 7-9.

[14] A.O. Igwegbe, J.O. Ugboaja, and E.N. Monago, Prevalence and determinants of unmet need for family planning in Nnewi, southeast Nigeria, International Journal of Medicine and Medical Sciences, 1, 2009, 325-29.

[15] C. Westhoff, and A. Davies, Tubal Sterlization Focus on the US Experience, Fert. Steril. 23(S), 2000, 913-22.

[16] K Kolcaba's (2015). Nursing Theories and Nursing Models, 2015 [Online], Available from: http://www.nursingtheory.org/theories-and-models [Accessed: 1/4/2016].

[17] C. Gordon-Maclean, and M.I Rodriguez, The safety, efficacy and acceptability of task sharing tubal sterilization to midlevel providers: a systematic review, Contraception, 89 (6), 2014, 504-11.

[18] G.O. Igberase, and P.N. Ebeigbe, Maternal mortality in a rural referral hospital in Niger Delta Nigeria, J Obstet Gynaecol, 27 (3), 2007, 375-8.

[19] J.T. Mutihir, and V.C. Pam, Overview of contraceptive use in Jos University Teaching Hospital North Central Nigeria, Journal of Clinical Practice, 11, 2008, 139-143.

[20] S. Hatcher, S. Sharon, V. Parag, and N. Collins, Problem-solving therapy for people who present to hospital with self-harm: Zelen randomised controlled trial, The British Journal of Psychiatry, 199 (4), 2011, 310-316.

[21] Y. Waheeb, A. Zeid, and A. El Faky, Community and Service Providers' Attitudes about Tubal Ligation for Medical Reasons, The British Journal, 2005

Table 1: Main themes and categories generated from the data

\begin{tabular}{|l|l|}
\hline \multicolumn{1}{|c|}{ Main themes } & \multicolumn{1}{c|}{ Category } \\
\hline Demographic profiles & Age \\
& Educational level \\
& Religion \\
& Tribe \\
& Number of children \\
\hline Awareness of family & Knowledge of family planning \\
Planning/contraceptives & Sources of information \\
& Choice of family planning \\
& Health education on family planning \\
\hline Knowledge of BTL & Awareness of BTL \\
& Information on BTL \\
& Health education of BTL \\
\hline \multirow{3}{*}{ Participants perception of BTL } & Individual belief on BTL \\
& Religious stand on BTL \\
& Decision on BTL \\
& Recommendation of BTL \\
\hline
\end{tabular}

Table 2: Participants' demographic profiles $(\mathrm{n}=18)$

\begin{tabular}{|c|c|c|}
\hline Profile & $\mathbf{N}$ & $\%$ \\
\hline Age group in years $18-29$ & 2 & 11.1 \\
\hline $30-39$ & 10 & 55.5 \\
\hline $40-49$ & 5 & 27.7 \\
\hline $50-59$ & 1 & 5.6 \\
\hline \multicolumn{3}{|l|}{ Educational level } \\
\hline Secondary & 3 & 16.7 \\
\hline Tertiary & 10 & 55.5 \\
\hline Post graduate & 5 & 27.7 \\
\hline Christianity & 11 & 61.1 \\
\hline Islam & 6 & 33.3 \\
\hline Others & 1 & 5.6 \\
\hline Yoruba & 12 & 66.7 \\
\hline Hausa & 4 & 22.2 \\
\hline Igbo & 2 & 11.1 \\
\hline Number of children $1-3$ & 12 & 66.7 \\
\hline $4-6$ & 6 & 33.3 \\
\hline 7 and above & - & - \\
\hline
\end{tabular}

